\title{
REPENSANDO EL TESTIMONIO: LA DISTINCIÓN ENTRE AGENTE Y PRODUCTO
}

\author{
RETHINKING THE TESTIMONY: THE DISTINCTION WITHIN \\ THE AGENT AND THE PRODUCT
}

\author{
María de los Ángeles González Coulon*
}

\begin{abstract}
RESUMEN: Este trabajo tiene como objetivo principal cuestionar la visión tradicional que se ha tenido de la prueba testimonial, planteando la necesidad de generar un concepto amplio de testimonio que permita incluir en su regulación y análisis otros testimonios en juicio. El análisis, desde una perspectiva amplia de testimonio, debe distinguir, en las etapas de conformación y valoración del material probatorio, entre quien realiza la declaración -el agente- y el producto de dicha declaración -testimonio propiamente tal-, porque de lo contrario, y de acuerdo a nuestra regulación civil actual, el agente termina contaminando el producto.
\end{abstract}

Palabras clave: testimonio, prueba testimonial, etapas actividad probatoria, testigo, declaración.

ABSTRACT: The main objective of this work is to question the traditional view regarding proof by testimony, raising the necessity of generating a wide concept of testimony that allows the inclusion of other testimonies in trials in its regulation and analysis. The analysis, from a widespread perspective of testimony, shall distinguish, in the stages of conformation and value of the evidentiary material, between the party making the declaration -the agentand the product of such declaration -testimony as such-, since otherwise, according to the civil law in force, the agent ends contaminating the product.

Key words: testimony, proof by testimony, probatory activities stages, witness, declaration.

\section{INTRODUCCIÓN}

El término testimonio ha sido, a lo largo del tiempo, examinado desde dos vertientes. La primera de ellas, dice relación con la prueba testimonial tradicionalmente entendida, es decir, desde la mirada de un tercero que percibió algo con alguno de sus sentidos, y la segunda, desde la desconfianza absoluta en lo que el testigo va a declarar, porque ese tercero podría estar, por un lado, influenciado por alguna de las partes o tener un cierto interés en el juicio, y por otro porque no se confía de lo que dicha persona percibió ${ }^{1}$. Esta manera tradicional de estudiarlo ha tenido como consecuencia que se olvide la importancia que el testimonio tiene en el proceso, las falencias de su regulación y, más aún, la posibilidad de proyectar dicha regulación a otros medios de pruebas que también pueden ser entendidos como testimonio. Así, esto ha producido que solo se estudie, en material civil, a

\footnotetext{
* Doctora (c) Universidad Autónoma de Barcelona. Profesora asistente Departamento Derecho Procesal, Facultad de Derecho, Universidad de Chile. Dirección postal: Pío Nono 1, Providencia, Santiago, Chile. Dirección electrónica: magonzalez@derecho.uchile.cl.

1 Gorphe (1971).
} 
través del listado de quienes pueden ser testigos, de cómo debe desarrollarse su declaración y cómo debe valorarse.

No obstante lo anterior, el escaso análisis de dicho medio de prueba -en comparación con la prueba científica, por ejemplo- es paradójico, porque si bien su estudio dentro del ámbito jurídico es menor comparativamente o excesivamente formal, es la forma en que hemos obtenido la mayoría de los conocimientos que tenemos, ya que muy pocas veces esos conocimientos están basados en experiencias primarias y propias de cada $u_{n o}^{2}$, sin embargo, hay un exceso de desconfianza en el mismo. Una de las posibles explicaciones al respecto, es quizás el exceso de relevancia que se le ha dado, dentro de la regulación de los distintos procesos a la prueba instrumental ${ }^{3}$ y hoy en día, a la sobrevaloración que experimenta la prueba científica tanto epistémica, otorgándole una infalibilidad que no tendría porque “(...) no constituyen por lo general un razonamiento de tipo deductivo, sino que están basadas prevalentemente en leyes estadísticas y sus resultados han de ser aún interpretados a la luz de otros datos (...)" ${ }^{4}$, como semántica ya que "(...) los resultados de la prueba dicen cosas distintas de las que en realidad dicen"s.

La situación descrita, de inmensa desconfianza y de un análisis meramente reglamentario de la prueba testimonial versus el resto de los medios de prueba se refleja claramente en el proceso civil chileno donde se ha señalado que la eficacia de este medio de prueba “(...) es dependiente en gran medida de la credibilidad de la persona que presta la declaración sobre el hecho" ${ }^{6}$, es decir, todo gira en torno al agente que realiza la declaración, olvidando el producto de la declaración de dicha persona. En otras palabras, la manera en que se aborda este medio de prueba ha implicado que el testigo contamine la declaración que efectuará.

La regulación civil chilena respecto al testimonio manifiesta plenamente las vicisitudes planteadas con antelación porque no solo mira el testimonio desde una perspectiva tradicional -como un tercero-, sino que enumera una serie de personas como inhábiles para declarar en juicio. Luego, menciona de forma detallada el procedimiento para deducir las tachas, el cual es a lo menos curioso ya que si bien deben formularse antes de la declaración del testigo, pueden fallarse en la sentencia definitiva. Finaliza regulándose, de acuerdo a los parámetros de un sistema de prueba legal o tasada, la forma en que esta prueba debe valorarse, dejando de lado la relevancia del testimonio como fuente de conocimientos.

Es por lo precedente, que este artículo tiene por objeto generar un nuevo concepto, centrado en la naturaleza jurídica de este medio de prueba, lo que creo es trascendental por la importancia que este tiene al ser una forma de adquisición de conocimiento ${ }^{7}$. No obstante, en la actualidad, aquello ha sido olvidado siendo analizada como una prueba de menor calidad $^{8}$ como consecuencia de que su examen se ha situado en torno al testigo y a la des-

2 VÁzquez (2015) p. 49.

VÁzQuez (2015) p. 9. TARUffo (2012) p. 416.

${ }^{4}$ GASCÓN (2013) p. 183.

GASCÓN (2013) p. 186.

6 Palomo et al. (2014) p. 330.

7 VÁzquez (2015) p. 49.

8 Adler (2017). 
confianza que se tiene en él, lo que hace necesario plantear un nuevo análisis que permita mirar en perspectiva el medio de prueba estudiado impidiendo que el testigo contamine la declaración que efectuará.

Esta contaminación a la que me he referido, ha derivado en la subvaloración general de la prueba testimonial ${ }^{9}$, impidiendo un examen correcto en las etapas de conformación y valoración de este medio de prueba lo que trae como consecuencia que el conflicto no pueda resolverse de manera correcta ni pueda tampoco cumplir con el propósito de búsqueda de la verdad. Se ha señalado que esto sucede por el poco interés en mejorar la institución probatoria en busca de los objetivos planteados ya que los sistemas judiciales tienen actualmente grandes aspectos subjetivistas ${ }^{10}$, lo que se ve reflejado en Chile, a pesar de tener un sistema de prueba legal o tasada.

En este artículo desarrollaré un re-análisis de este medio de prueba a través de un concepto amplio de prueba testimonial. Luego, dentro de dicho concepto identificaré dos elementos que creo deben abordarse en el mismo nivel, cuales son, quien realiza la declaración, al que comúnmente se le llama testigo y aquí se denominará, sujeto o agente, y el resultado o contenido de dicha declaración que llamaré producto. En un primer momento, plantearé el examen separado de los mismos para un mayor entendimiento del testimonio, y por qué ello trae importantes ventajas aparejadas que también se revisarán. Este análisis se realizará tanto en la etapa de conformación del material probatorio como en la de valoración del mismo.

El desarrollo de este trabajo estará estructurado de la siguiente manera: (1) efectuaré una breve referencia a la visión tradicional del testimonio en nuestro proceso civil; (2) luego, realizaré una propuesta respecto a una definición amplia de testimonio, para como consecuencia de aquello, (3) plantear la necesaria distinción entre los dos elementos que contiene la definición de testimonio, como son el agente y el producto, destacando la importancia de aquello. Terminaré, (4) entregando ciertas conclusiones generales al respecto.

\section{VISIÓN TRADICIONAL DEL TESTIMONIO}

La visión tradicional del testimonio se ha centrado en el estudio del mismo desde la perspectiva de una declaración sobre ciertos hechos que realiza un tercero. En dicha concepción tradicional se ha definido él mismo como la "declaración sobre un hecho relevante para el objeto de la prueba, realizada por un sujeto que afirma tener conocimiento de tal hecho"11, es decir, no se realiza distinción alguna entre los elementos que el testimonio contiene, siendo entonces el agente -el testigo- y el producto de su declaración, un todo.

La definición anterior, es la realizada por la doctrina basándose en los elementos que el propio legislador le ha proveído -ya que el legislador no lo ha definido-. Dichos elementos son principalmente, el listado de quienes pueden declarar como testigos, la forma ordinaria y ciertas formas especiales para realizar la declaración del testigo, y cómo debe va-

\footnotetext{
9 Quintana (2008) p. 102.

10 Ramos (2019) p. 36.

11 Palomo et al. (2014) p. 329.
} 
lorarse dicha prueba. Es decir, es una mera descripción, que no realiza distinciones respecto al agente y el producto de la actividad, ni entre las distintas etapas de la actividad probatoria.

Este tratamiento tradicional y meramente descriptivo del testimonio, se encuentra reflejado de manera clara en nuestro Código de Procedimiento Civil (en adelante CPC), así como también en el estudio de los nuevos procesos, que si bien es cierto han tratado de realizar una cierta evolución en materia probatoria, igualmente mantienen un sesgo tradicional en el tratamiento de la misma. Así, si bien la valoración de la prueba testimonial en las nuevas leyes, se rige por las normas de la sana crítica, existiendo una diferencia entre el momento de conformación del material probatorio y el de valoración; en el caso de la prueba testimonial, no hay un análisis pormenorizado y sesgado entre el testigo y su testimonio ni en sede de inclusión ni en sede de valoración, lo que finalmente hace que se mantenga la visión conservadora sostenida.

Como ya se esbozó al inicio, la visión tradicional al referirse al testimonio, siempre lo hace desde la perspectiva del hablante, testigo o agente, y ello rebota al producto de la declaración. Desde esta visión, la prueba testimonial vendría siendo un medio de prueba en que un tercero -el testigo- declara respecto a la ocurrencia de un hecho, entremezclándose con la misma definición que a ratos se da del testigo. Así, el testigo sería "una persona de quien se supone que sabe algo relevante sobre los hechos del caso a quien se interroga bajo juramento con el fin de saber lo que ella conoce sobre tales hechos" ${ }^{12}$, o como otros autores lo caracterizan, la "persona natural -las personas jurídicas no perciben sensorialmente datos o informaciones, solo pueden suministrar informes- que como fuente de un hecho o hechos declara en el proceso sobre su percepción y conocimiento de hechos y circunstancias pasadas"13. Otra parte de la doctrina, solo enumera sus características, es decir, el testigo es un tercero indiferente dentro del proceso; que declara sobre hechos precisos, y conoce los hechos por haberlos percibido por sus propios sentidos o el dicho de otro ${ }^{14}$.

Respecto a la declaración propiamente tal que este tercero realiza, pocas definiciones se refieren a la misma, y siempre lo hacen desde la arista del agente. Así, se ha definido como "el acto dirigido a verter en el proceso ese hecho pasado mediante la declaración del testigo" 15 , o como un "acto humano dirigido a representar un hecho no presente"16.

La visión clásica jurídica del testimonio, centra su atención no en definirlo exactamente ni establecer sus elementos fundantes, sino que en analizarlo desde la mirada del agente y centrar en él la posible caracterización del testimonio, sin realizar ningún tipo de distinción. Se establece que la posible inclusión de una declaración estaría dada solo por las características personales del testigo y que la valoración del testimonio también estaría centrada en la credibilidad del mismo y no en el contenido de su actividad.

En palabras simples, al analizar el estudio que se realiza del testimonio, lo que se hace es definir quién es testigo y luego transcribir la regulación establecida por el legisla-

\footnotetext{
TARUFFo (2008) p. 62.

Rivera (2011) p. 186.

Maturana y Montero (2010) p. 985.

Rivera (2011) p. 186.

6 Carnelutti (1982) p. 121
} 
dor. La estructura se define entonces por: concepto, clasificación, limitaciones, iniciativa, oportunidad procesal para hacerla valer, obligaciones y derechos de los testigos, capacidad y desarrollo de la declaración ${ }^{17}$.

En el ámbito del proceso civil nacional, todo lo dicho es claro porque toda la regulación de nuestro CPC gira en torno al agente y las razones para no creer en él. Así, (i) se enumera a los inhábiles para declarar, quienes podríamos entender son personas poco creíbles y que por lo tanto sus declaraciones no deberían tener ningún valor. Esto por supuestas relaciones personales con la parte que lo presenta, sin considerar que esa posible cercanía podría entregar información sumamente relevante y de total interés para resolver el caso; (ii) se tratan las tachas, que está vinculado a lo anterior; (iii) se enumeran quienes están exceptuados de declarar, lo que tiene su fundamento en situaciones de privilegio o dignidad, pero que también obvian la posibilidad de entregar información relevante; (iv) lista a quienes pueden declarar, pero en su domicilio; (v) menciona la forma en que van a declarar; y (vi) al estar ante un sistema de prueba legal o tasada determina la forma en que deben valorarse las declaraciones del testigo, cuyo centro es el agente, y nunca el contenido de su declaración. Un ejemplo de ello está constituido por el artículo 384 del CPC que señala que un testigo imparcial y verídico constituirá presunción judicial a diferencia de dos o más testigos contestes en el hecho y en sus circunstancias esenciales constituirán plena prueba.

Cabe destacar que incluso la normativa referida a la valoración de este medio de prueba y que utiliza la terminología "declaraciones de testigos", centra su análisis en estos últimos y no en el contenido de aquella. Por ejemplo, el centro del numeral $1^{\circ}$ del artículo 384 CPC no es la declaración sino el hecho de que la realiza un testigo imparcial o verídico, lo mismo que sucede con el numeral $3^{\circ}$ que si bien inicia con el supuesto análisis de la declaración, la valoración estará dada por la fama o imparcialidad de los testigos. En concreto, lo único que hace referencia como tal a la declaración, a mí modo de ver, es aquello que señala que la misma deberá conformarse con otras pruebas del proceso.

Todo lo anterior a nivel legislativo, también se refleja en la doctrina donde en gene$\mathrm{ral}^{18}$ no se hace más que definir de manera tradicional este medio de prueba y enumerar el procedimiento. Esto, sin mayores cuestionamientos y siempre centrado en la figura del agente ${ }^{19}$.

En definitiva, el estudio del testimonio está enfocado en la figura del testigo dejándose de lado su declaración, y así la valoración del mismo se enfoca, en materia civil, en el número de testigos ${ }^{20}$. Lo anterior, trae aparejados dos problemas que resolver, el primero la falta de distinción entre agente y actividad, lo que es de suma importancia, porque una cosa es quien realiza la declaración y otra, muy distinta, es el contenido de la misma. Ergo, en ciertas ocasiones puede ocurrir que se decida, en un primer momento, admitir que una

\footnotetext{
17 Palomo et al. (2014) Maturana y Montero (2010).

18 Respecto a la doctrina nacional, solo CONTRERAs (2015) ha ido más allá en esta materia desarrollando en su trabajo aspectos de la sicología del testimonio pertinentes para la valoración del mismo y la forma en que debe valorarse este medio de prueba en segunda instancia.

19 Véase por ejemplo los artículos 357 y siguientes del Código de Procedimiento Civil.

20 Artículo 384 del Código de Procedimiento Civil.
} 
determinada persona declare en juicio, valorando posteriormente su credibilidad; en otras circunstancias, puede darse que por muy confiable que sea dicha persona, puede ser que lo que vaya a declarar no tenga relevancia en el juicio o, de tenerla, su relato incluya hechos imposibles de suceder. Al revés, puede ocurrir que la persona del testigo no sea totalmente creíble, pero que su declaración tenga un valor fundamental dentro del proceso, y permita apoyar una de las tesis presentadas por las partes. Así, este primer problema nos vincula con el segundo, cual es el hecho de que al realizar dicha distinción tampoco podemos analizar correctamente al agente y su declaración en los distintos momentos de la actividad probatoria que también se confunden en materia civil, cuales son lo de conformación y de valoración del material probatorio.

\section{PROPUESTA DE UNA DEFINICIÓN AMPLIA DE TESTIMONIO}

Para afirmar el conocimiento de cualquier aspecto de la vida diaria, utilizamos el testimonio como fuente de información. El testimonio es una forma de aproximación a ciertos hechos, confiándose per se y sin cuestionamientos mayores en lo que se nos señala, y sin tener, al mismo tiempo, forma de verificar lo que se nos ha dicho, o pudiendo verificarse solo a través de otros testimonios ${ }^{21}$, como menciona Thagard "cuando alguien te cuenta algo, ¿debes creerle? Este problema es óbice en el derecho, los negocios, la ciencia y en la vida diaria. Por ejemplo, cuando un juez debe decidir en base a un testimonio"22. De hecho, tomamos decisiones importantes de nuestra vida basado en esta fuente de conocimiento.

Como hemos señalado, la mayoría de los conocimientos que tenemos, los hemos obtenido a través de testimonios ${ }^{23}$, lo que se puede ilustrar a través de dos ejemplos; el primero dice relación con nuestras experiencias familiares, ya que muchas de las historias que contamos y repetimos constantemente sobre nuestras familias no las hemos vivido nosotros, como experiencia primaria, sino que han sido contadas por nuestros ascendentes, no obstante ello, cada uno de nosotros las reitera, añadiendo ciertas aristas que nos han relatado diversas personas, como si fueran completamente reales, sin cuestionamientos y como si las hubiésemos vivido. Un segundo ejemplo, son los conocimientos que el profesor de historia nos transmite, quien nos menciona fechas de ciertos acontecimientos y detalles que nosotros aprendemos y luego transmitimos a las generaciones venideras, sin preguntarnos si el hecho relatado realmente ocurrió, o si de ocurrir, sucedió en la fecha mencionada.

No obstante lo anterior, el testimonio ha sido analizado con cierta superficialidad, por lo que creo que debe estudiarse y conocerse en mayor medida. Así, como revisaremos, para muchos el testimonio es solo un acto de comunicación, sin embargo, creemos que este va mucho más allá porque implica realmente una transferencia de conocimientos que realiza un agente (algunos lo denominan hablante) a una determinada audiencia. Dicha audiencia no solo recibe dichos conocimientos, sino que con esa información toma decisiones importantes sin cuestionar, en la mayoría de los casos, la información proporcionada ${ }^{24}$.

\footnotetext{
21 PÁez (2014) pp. 99-100.

22 Thagard (2005) p. 295.

23 VÁzquez (2015) p. 49.

24 VÁzQuez (2015) pp. 49 ss.
} 
Así, para la elaboración de un concepto de testimonio que no solo nos permita definirlo sino también entender los problemas y formas de justificación del mismo, es que utilizaremos el desarrollo que la epistemología ha tenido al respecto. Luego, el objetivo, será, tomándome de las ideas elaboradas por Páez en esta temática “(...) más bien examinar cómo es entendida la prueba testimonial en el derecho, determinar cuál de esas posiciones es más afín, y utilizar la especificidad de la prueba testimonial para enriquecer un debate filosófico que a veces se queda en un plano muy general y no entra a examinar los diferentes usos que se le da al testimonio"25.

Utilizaré la epistemología como herramienta de comprensión del testimonio porque la misma ha sido una ciencia que de una forma u otra ha permitido entender los razonamientos probatorios ${ }^{26}$, principalmente en el momento final de la toma de decisión y de motivación de la misma ${ }^{27}$. Luego, para una revisión ordenada de los posibles conceptos de testimonios que pretendo analizar, comenzaré con aquella idea en que el testimonio solamente es un acto de comunicación, para luego dar paso hacia aquella que esboza que el testimonio es una fuente de información, y que, por tanto, a través de él estaríamos transfiriendo conocimiento y generando creencias.

En primer término, se ha mencionado que el testimonio al igual que la memoria es solo una forma de transmitir el conocimiento ${ }^{28}$, por ende, "se difunde el conocimiento a través de la comunicación" ${ }^{29}$. Ahora, esto no impide que en ciertos casos este testimonio pueda llegar a generar conocimiento ${ }^{30}$.

De esta manera, entender el testimonio como un acto comunicativo, implica en el ámbito jurídico, concebirlo como la "transmisión del conocimiento de un hecho adquirido por el testigo" ${ }^{31}$, existiendo -según Dosi- dos fases, cuales serían la de adquisición de dicho conocimiento y la de transmisión del mismo, centrándose en materia procesal solo en la segunda de ellas, siendo el testigo "(...) un simple instrumento de transmisión de aquel hecho"32.

Sin embargo, esta idea del testimonio como acto de comunicación, igualmente se vincula con información y conocimiento ${ }^{33}$, y por eso creo que vincular el testimonio solo con la idea de comunicación es un concepto que se observa incompleto. En el ámbito jurídico, el testimonio va más allá de un acto de comunicación porque será el antecedente necesario para la resolución de un conflicto, ya nos mencionaba Coady, quien ha desarrollado de forma completa la idea de testimonio, que este es un acto de habla con una cierta intención, al definirlo como un "acto ilocutorio" que es llevado a cabo bajo ciertas condiciones e intenciones ${ }^{34}$.

\footnotetext{
25 PÁEZ (2014). p. 100.

26 NieVA (2010) p. 99.

27 Nieva (2010) pp. 107 y 110.

28 LACKEY (1999) p. 471

29 Graham (1997) p. 231.

30 LACKey (1999) p. 490

31 Dosi (2016) p. 3.

32 Dosi (2016) p. 6.

33 Adler (2017).

${ }^{34}$ Coady (2002) p. 25
} 
Así, sin obviar que a diferencia de la memoria y la percepción, el testimonio tiene una intención comunicativa ${ }^{35}$, esto no obsta a la adquisición de conocimiento y al traspaso de información que implica, donde es posible distinguir tres elementos: "a) la expresión de información, creencias o conocimiento mediante un acto de comunicación; b) una conexión razonable entre lo dicho por el hablante y lo adquirido por la audiencia; c) la información adquirida al menos en parte mediante ese acto de comunicación" ${ }^{\prime 6}$. Como bien lo explica Vásquez, el testimonio es una práctica social que se materializa a través de un acto de habla, pero del cual, querámoslo o no, obtenemos conocimiento ${ }^{37}$.

En otras palabras, si bien la idea de testimonio se desarrolla como un acto comunicativo, finalmente "el concepto general de testimonio supone la existencia de al menos dos agentes, el hablante y la audiencia, con distintos roles, características y exigencias (...)”, que si bien se entienden insertos en un acto de comunicación, el acto del testimonio tiene un determinado significado, siendo para la audiencia una fuente de conocimiento o creencias, y por tanto suponiendo la existencia de dos asuntos, el primero es que los oyentes pueden adquirir conocimiento a través del testimonio de otros, y que los hablantes tienen ese conocimiento.

El testimonio entonces es una fuente de conocimiento, más que un mero acto comunicacional, que debe ser interiorizado por la audiencia, ya que al ser tratado como un medio de prueba, proporcionará los conocimientos para que luego el juez -la audiencia- pueda tomar una decisión. A lo señalado, se suma que la audiencia no debe conocer ex ante lo que el hablante afirma, y/o no debe tratarse de una mera diferencia de acceso a las pruebas relevantes que pudiese suscitar diferencias de opinión o desacuerdos en los participantes en el acto de comunicación ${ }^{38}$. Ergo, creo que revisar el testimonio solo como un acto de comunicación otorga una mirada demasiado restringida, ya que el acto de comunicación es solo uno de los elementos que lo componen surgiendo la necesidad de que dicho acto se conecte con lo que la audiencia adquiere, para que esta última absorba parte del conocimiento.

En definitiva, y en virtud de que el objetivo de este artículo es lograr un concepto de testimonio amplio que nos permita establecer su naturaleza jurídica, y de la mano de ella, tratar de incluir también otros medios de prueba, es que tomaremos la posición amplia en que el testimonio es una fuente de conocimientos y creencias más que meramente un acto comunicacional que deberá ser absorbido por la audiencia. La justificación de lo anterior es la necesidad de “(...) construir en orden al sistema, una amplia categoría del testimonio, que contenga tanto la declaración representativa de las partes como la declaración representativa de los terceros, lo que no excluye que dentro de la amplitud de esta categoría deba trazarse una distinción según el criterio de la cualidad del testigo, en relación a su posición en el proceso; con tanta mayor razón cuanto más acusada sea la diversidad de la regulación de las dos fuentes de prueba" 39 .

\footnotetext{
35 Adler (2017).

6 VÁsQUEZ (2015) p. 50.

37 VÁSQUeZ (2015) p. 51

38 VÁzquez (2015) p. 52

39 Carnelutti (1982) p. 149.
} 
Por lo anterior, definiremos el testimonio, para su aplicación en el ámbito jurídico, como un acto de comunicación en que el hablante traspasa o expresa conocimientos, información o creencias mediante dicho acto. Luego, podemos señalar que el recién denominado hablante en sí -es decir, quien expresa la información, creencia o conocimiento- es quien tradicionalmente se conoce como el testigo, y lo que expresa -es decir la información, creencia o conocimiento- lo que tradicionalmente se conoce como testimonio. Además, e independiente del tipo de conocimiento que transfiera, epistemológicamente será un testimonio ${ }^{40}$. En este último sentido, distinguimos los dos elementos que anunciamos, el hablante, sujeto o agente, por un lado, y el producto o contenido, por otro.

Respecto ahora a la distinción entre agente y producto que planteo, si bien puede parecer algo antojadiza y rebuscada, al analizarlo en profundidad para determinar su inclusión y valoración en juicio, podremos ver que estos elementos se tornan completamente relevantes ante los problemas y justificaciones que el testimonio presenta, siempre que lo que busquemos sea analizar el testimonio de una manera más profunda, que nos permita determinar cómo introducirlo en juicio y por sobre todo cómo el juez podrá utilizarlo para tomar una decisión. En este sentido, la distinción se torna completamente trascendental porque el hecho de no distinguir entre el agente y el producto, puede generar ciertas dificultades que eventualmente podrían gestar ciertas arbitrariedades.

Si aspiramos, como señala Taruffo, introducir al juicio la información que le permita al juez realizar un análisis racional, y entregar al juzgador la opción de juntar información relevante para la determinación de la credibilidad del testigo, siempre en torno a criterios objetivos $^{41}$, esto solo puede ocurrir realizando de forma segmentada los análisis propuestos, como a continuación revisaremos.

\section{ANÁLISIS DIFERENCIADO DEL AGENTE Y SU PRODUCTO}

\subsection{AgENTE y PRODUCTO}

He venido señalando que, al revisarse la prueba testimonial, tradicionalmente el centro de la misma ha sido el testigo. Es por ello que, de la mano del concepto amplio esbozado, he propuesto distinguir entre dos elementos que deben situarse en un mismo nivel, cuales son, el agente o sujeto, y el contenido de su declaración o producto.

Los conceptos respecto a los elementos planteados, no son terminologías propias de la doctrina procesal como tal, pero de todas formas son posibles de insertar dentro del concepto amplio entregado en precedencia y permiten dejar de lado las concepciones simplistas y con poco análisis de los conceptos tradicionales.

Respecto al elemento que he denominado producto, este no será entendido más que como el resultado de una actividad ${ }^{42}$. Así, en este caso, será el resultado de la declaración, como parte de la ritualidad, que realiza el agente o sujeto -que ya definiré-. En otras palabras, será el resultado de la declaración, la que ha sido entendida como "el acto dirigido a

\footnotetext{
40 Nieva (2010) p. 215.

41 TARUfFo (2012) p. 418

42 Guastini (2014) p. 31.
} 
verter en el proceso ese hecho pasado mediante la declaración del testigo" ${ }^{33} \mathrm{o}$, como planteó Carnelutti, "el acto humano dirigido a representar un hecho no presente" ${ }^{44}$.

El producto, no es propiamente la actividad en sí, que es mera formalidad, sino que será lo que dicha actividad nos entrega, es decir, el conocimiento o creencia que nos transmite, y que será, en el caso de un juicio, uno de los antecedentes necesarios que permitan finalmente tomar una decisión respecto al conflicto planteado.

El concepto de agente no es nuevo en el ámbito de la filosofía, en circunstancias que dentro de un proceso podemos encontrar distintos sujetos con diversidad de agendas. Así, en general, es necesario entender que el agente es un sujeto que conoce algo, pudiendo ser un productor de cambios en el mundo si se cuenta con las capacidades para realizar voluntariamente, entender y explicar dichos cambios ${ }^{45}$, resultando entonces un factor clave la voluntariedad, distinguiéndose así el sujeto -agente de otros objetos ${ }^{46}$. En otros términos, "un agente es un ser con capacidad para actuar, y agencia denota el ejercicio o manifestación de esa capacidad" ${ }^{47}$, encontrándose ellos en todas partes interactuando entre $s^{48}{ }^{48}$.

Esta entidad que hace algo, en palabras de Niño y Marrero, “(...) puede ser individual, como los seres humanos, colectivo, como un equipo de fútbol, o institucional, como la NASA" ${ }^{49}$. Luego, cada uno de ellos tiene unas respectivas agendas, que vendrían siendo "los objetivos de los agentes", respecto a los cuales los distintos agentes tienen diversos recursos para resolverlas, relativos principalmente al tiempo, a sus habilidades e información y que pueden ser relativas a la formación de una creencia o de presentación y defensa ${ }^{50}$.

El caso del agente que nos convoca en esta tesis, es decir de quien transfiere el conocimiento o creencia, siempre se plantea desde la idea de la atribución de ciertos conocimientos. Es por lo anterior, que el hablante debe aseverar (idealmente) solo aquello con respecto a lo cual cumple cierto requisito epistémico que apoye su verdad ${ }^{51}$. Este puede ser que conozca lo que afirma, que tenga una creencia en mayor o menor medida justificada o que sea por lo menos razonable creer lo que afirma ${ }^{52}$, ya que finalmente dicho agente "es responsable de la verdad de lo que dice" 53 .

Dentro del caso específico del proceso, este agente que conoce algo y cuyo papel es narrar dicho conocimiento, tiene ciertas particularidades. En primer lugar, se tienen expectativas de dicho conocimiento que no son acordes con lo que él realmente posee, es decir, se le atribuyen mayores conocimientos; en segundo término, se le mira con recelo en base a facto-

\footnotetext{
43 Rivera (2011) p. 186.

44 Carnelutti (1982) p. 121.

45 Figueroa (2016) p. 146.

46 Figueroa (2016) p. 148.

47 SChlosser (2015).

48 SChlosser (2015).

49 NiÑo et al. (2015) p. 197.

50 Niño et al. (2015) p. 198.

51 LOSADA (2015). p. 7.

52 LOSADA (2015). p. 7.

53 LOSADA (2015). p. 7.
} 
res como el lenguaje no verbal, estereotipos y prejuicios sociales ${ }^{54}$, pero como tercer aspecto, las formalidades de dicho proceso le permiten a la audiencia creer o no en él. Teniendo ello en cuenta, el agente para este trabajo será aquel sujeto que conoce algo y que al transferir dicho conocimiento dentro de un juicio, aportará una razón al juzgador para formar la creencia en la proposición correspondiente que es aquella expresada en el acto testimonial ${ }^{55}$.

\subsection{NECESIDAD DEL ANÁLISIS DIFERENCIADO}

La pregunta que surge respecto a lo que hemos venido desarrollando es por qué sería necesaria realizar la distinción entre el agente o sujeto y el producto o contenido de la declaración dentro de un proceso judicial, y consecuencialmente por qué ello implica una revisión de los planteamientos procesales más tradicionales.

Respecto a la primera de las interrogantes, creo que Páez lo refleja muy bien al señalar que "la valoración final de un testimonio dependerá por tanto de dos variables muy dispares. Por un lado, tenemos la credibilidad y la competencia del testigo, y es en torno a estas que girarán los alegatos de las partes; por el otro, tenemos la relevancia, el poder explicativo y la fuerza probatoria del testimonio, que constituyen la base objetiva para construir la fortaleza de la prueba testimonial. La actitud epistémica más racional será entonces la de invertir el mayor esfuerzo en justificar/refutar aquellas afirmaciones de un testigo que tengan el mayor valor informacional" 56 . Luego, que un testimonio esté justificado no quiere decir que se acepte dicha justificación.

Como he reiterado, la desconfianza general al testimonio se debe a que el centro del análisis está en la desconfianza en el testigo, sin importar mayormente el contenido de la declaración. A ello se suman, en el caso del derecho chileno, a la existencia de motivos de tacha que reflejan lo anterior e implican que per se el juzgador deba desconfiar de ciertas personas por la existencia de cierto tipo de relaciones, de esta manera a un grupo de personas "se les ha colocado la etiqueta de interesados, no se confía de su testimonio, y se procura alejarlos del proceso, o al menos tratarlos con la prevención que impone una tacha o incluso una dispensa" 57 .

Estas dos situaciones olvidan, como bien se exponía, que la credibilidad del agente debe ser independiente de las supuestas relaciones con alguna de las partes, y que además, hay otro elemento, cual es la declaración misma o producto, que debe evaluarse según su relevancia, poder explicativo y fuerza probatoria, más allá de si confiamos en el agente. En otras palabras, el testigo podría ser un mentiroso, pero lo que le debiese importar al proceso, epistémicamente hablando, es saber si los hechos son verdaderos o falsos, y no si el testigo es sincero o no, es decir, un testigo mentiroso podría ser igualmente una fuente de corroboración si es luego confirmado ${ }^{58}$.

\footnotetext{
34 Coloma et al. (2009) pp. 328-335.

5 Losada (2015). p. 7.

56 PÁEz (2014) p. 115.

57 Nieva (2010) p. 266.

58 Ramos (2018) p. 142.
} 
Creo que esta distinción, que no se realiza realmente ni por el legislador ni el juzgador, es trascendental en los momentos de conformación y valoración del material probatorio. Teniendo en consideración que para que el juzgador sea capaz de decidir sobre un caso concreto, igual que en cualquier decisión que tomamos a diario, se hace necesario contar con todos los antecedentes posibles. Luego, "(...) la evaluación de los testimonios se hará -en sede judicial- a base de tres criterios distintos, esto es, admisibilidad, relevancia y calidad epistémica" 59 . Es así, como si lo que buscamos finalmente al momento de tomar una decisión es disminuir el error, debemos entender que las probabilidades de acierto del juzgador van a estar vinculadas a la cantidad de información que este posee.

El primer problema que surge en el proceso civil chileno es la inexistencia de un momento de conformación del material probatorio, aunque así y todo evidenciamos que, aunque discutible porque no es claro si son en todos los casos un ejercicio de exclusión o de valoración, las tachas tienen como efecto la supresión de ciertas personas en el proceso, y consecuencialmente de sus declaraciones producto de ciertas relaciones o supuestos intereses en el juicio. Es así como el examen del agente o sujeto contamina entonces la entrada en juicio de una declaración cuyo contenido puede ser útil para la resolución del conflicto ${ }^{60}$.

$\mathrm{Al}$ respecto, creo que si nos situamos en un momento de conformación del material probatorio, no debiese en este examinarse al agente como tal, sino que solamente, y de acuerdo a criterios ya esgrimidos, como utilidad y pertinencia, solo debiese analizarse la declaración que efectuará.

Más concretamente, creo que solo debe realizarse un examen de relevancia y admisibilidad en torno al producto o contenido de lo que va a declarar y no respecto al agente o sujeto $^{61}$, y que el examen de este último siempre debe realizarse en la etapa de valoración de la prueba distinguiendo, por una parte, la evaluación de las características personales del agente y por otra, la declaración en torno a las razones epistémicas que se dan para creer en ella.

Entonces, si nos centramos en el agente, su análisis debiese venir en la etapa de valoración, aunque siempre distinguiéndolo de la valoración del producto, ya que en este momento también se da que quienes estiman que las tachas corresponden ser evaluadas en la etapa de valoración, vuelven a centrar en ellas la atención y nuevamente ignorar la declaración.

En el momento de la valoración entonces deberá distinguirse, evaluando el juzgador respecto al agente "(...) si es un hablante que posee credenciales epistémicas apropiadas sobre el tema que respalden la verdad de lo que es dicho (sean estas credenciales conocimiento, justificación o alguna otra cosa), o más precisamente si está ejerciendo su competencia en esa ocasión -o alternativamente, si hay indicaciones de lo contrario. Si tal reconocimiento tiene lugar, y si lo que es dicho mediante el testimonio es verdadero, la audiencia habrá formado una creencia justificada de modo tal que dé lugar a conocimiento" ${ }^{2}$. La pregunta es si esa creencia se basa en otras evidencias (reduccionismo) o sobre la habilidad recognoscitiva sobre la situación testimonial ${ }^{63}$.

\footnotetext{
59 Coloma et al. (2009) p. 305.

60 Framarino (1995) p. 70.

61 ZuCKerman (2013) p. 1037.

62 Losada (2015). p. 15.

63 Losada (2015). p. 16.
} 
Respondiendo la segunda pregunta que señalamos al inicio, sobre cómo lo planteado hace que re-analicemos las ideas más tradicionales sobre la prueba testimonial, al respecto, debo señalar, en primer término, que esta idea amplia de testimonio permite, eventualmente, hacerla extensiva a otros medios de prueba que epistémicamente son también testimonios, ya que como bien nos menciona Muñoz Sabaté, “(...) entre el confesante y la confesión, o entre el testigo y el testimonio, no media más distinción que la del punto de vista: ambos no son dos hechos diversos, sino uno mismo contemplado por el derecho y por el revés" ${ }^{64}$. Luego, la misma distinción entre agente y producto, con ciertos matices podríamos observarla en la declaración de la víctima o en la evaluación del perito.

En segundo lugar, esta distinción es distinta a las ideas tradicionales porque involucra no solo dejar atrás el centralismo del agente y situarlo de igual a igual con el producto, sino que además conlleva un ejercicio adicional que es la distinción de los elementos en cada uno de los momentos probatorios señalados, pero para concluir con la evaluación conjunta de ellos. Así, como menciona Fernández, respecto a la declaración de partes, pero aplicable a cualquier tipo de testimonio -si tomamos un concepto amplio del mismo-, al tratarse de requisitos aisladamente considerados, estos no permiten concluir por sí solos la atendibilidad de la declaración como suficiente prueba de cargo, y por tanto deberán presentarse de manera conjunta ${ }^{65}$.

Así las cosas, la distinción que he venido sosteniendo no radica en absoluto en eliminar el examen del agente, sino que más bien busca situar en el mismo plano y no olvidar el examen del producto porque no es posible sostener que un testigo mentiroso realice una mala declaración y viceversa, siendo la única posibilidad un examen independiente y objetivo de los dos elementos -agente y producto- ${ }^{66-67}$.

El planteamiento que propongo sobre distinguir entre agente y producto, se deriva de que si bien hay casos en que para verificar por parte del juzgador si lo que se relata es efectivamente creíble o no, se hace necesario examinar la persona del testigo porque "un primer tipo de mecanismos cuyo propósito es verificar la fiabilidad de los testimonios tiene que ver con la persona del testigo" ${ }^{68}$, o porque la atribución de méritos epistémicos de una declaración podría no estar completamente asociada a lo que se haya dicho, "la atribución de méritos epistémicos de una declaración de testigos podría no estar asociada al significado de lo que haya sido dicho, sino que podría ser la resultante de ciertas inferencias realizadas a partir de factores tales como la conducta previa del emisor o la manera en que se presenta su declaración. Lo que aquí se lleva a cabo es fundamentalmente un juicio acerca de ciertas características del emisor del mensaje, las cuales impactarían en la atribución de credibilidad de lo que se dice y, consecuencialmente, en los méritos epistémicos a aquello que ha sido declarado" ${ }^{\prime \prime}$.

\footnotetext{
64 MuÑoz (2001) p. 283.

65 FERnÁNDEZ (2009) p. 195.

66 NieVA (2010) p. 222.

67 Framarino (1995) p. 73.

68 Taruffo (2008) p. 63.

69 Coloma et al. (2009) p. 328
} 
Hay otros casos en que las características del agente no estarían asociadas al producto de su declaración, pero que ese constante centralismo en el mismo, que se ve reflejado en las legislaciones estudiadas, hace que igualmente se olvide la posibilidad de la realización de inferencias en torno a la declaración y se termine examinando en torno al sujeto. Todo lo dicho, será analizado a continuación a propósito del caso chileno.

\subsubsection{Etapa de conformación del material probatorio}

En el ámbito jurídico, la etapa de determinar con que material probatorio contamos y con cuál no, está dado por el momento de la inclusión, pudiendo ser la forma en que se determinará dicha inclusión distinta dependiendo del sistema procesal, es decir debemos establecer qué elementos incluiremos en el proceso y cuáles no serán incorporados ${ }^{70}$. Ergo, "en términos generales, los problemas de admisibilidad serán resueltos por la aplicación de reglas más bien precisas que definen cuando cierta información puede ser presentada en juicio y cuando debe ser excluida de este" 71 . En definitiva, en esta etapa, se nos dice lo que será parte de un argumento ${ }^{72}$, tomándose en consideración por una parte la relevancia y por otra la admisibilidad del medio de prueba ${ }^{73}$.

Así las cosas, la relevancia está referida a determinar la utilidad y falta de redundancia de un medio de prueba, es decir, "en todos los sistemas, el principio tiene una función negativa o excluyente, y opera como una norma según la cual algunos medios de prueba deben ser directamente rechazados (...). En algunos sistemas, además, el principio tiene principalmente un significado incluyente, pues establece que todos los medios de prueba relevantes deben ser admitidos" ${ }^{\text {74 }}$. Realizada o no la distinción anterior, la consecuencia de la aplicación de dichos criterios es la misma, cual es, la exclusión de la prueba ofrecida.

Este principio de la relevancia se vincula al principio de economía procesal, entendiendo que no se puede permitir en juicio la rendición de todos los antecedentes con que eventualmente se podrían contar, buscando que no se introduzcan pruebas que a priori son inútiles o que lógicamente no tienen conexión con el proceso. La utilidad de la misma podrá determinarse a través de un criterio respecto a la relevancia del hecho a probar, y de la posibilidad de formular inferencias probatorias desde el hecho secundario sobre el que versa la prueba hasta el hecho que necesita probarse $\mathrm{e}^{75}$. En otras palabras, solo será prueba lo que sea relevante en un proceso $^{76}$.

La relevancia ha sido entendida como un principio hipotético, de esta manera, toda aquella prueba que consideremos hipotéticamente relevante, debe ser, en principio, incluida en el proceso ${ }^{77}$. Según Páez, "es necesario que exista un grado mínimo de probabilidad,

\footnotetext{
70 TARUfFo (2008) p. 37.

71 Coloma et al. (2009) p. 305

72 Anderson et al. (2015) p. 359.

73 Ferrer (2007) pp. 41-45.

74 TARUfFo (2008) p. 41.

75 TARUfFo (2011) p. 365.

76 TARUfFo (2011) p. 365.

77 En este sentido autores como Stein lo han descrito como el Principio de máxima individualización, PMI por sus siglas en inglés. STEIN (2005) p. 100.
} 
un umbral a partir del cual el juzgador puede admitir la evidencia. (...) Un fuerte efecto sobre la probabilidad de una hipótesis indica la alta relevancia de la evidencia, un efecto que otros hechos menos relevantes no tienen"78.

Determinados dentro del proceso los elementos que se entienden como relevantes, y por tanto, deberán incluirse, queda entonces realizar un segundo análisis vinculado con el hecho de si el medio de prueba presentado es jurídicamente admisible. En otras palabras, se deberá establecer si el sistema procesal en el que se está actuando contiene normas de exclusión del mismo por ciertas razones, amparadas por lo general, en valores, las que han sido llamadas reglas contra-epistémicas ${ }^{79}$.

Las reglas contra-epistémicas pueden entenderse como aquellas "que no favorecen o incluso entorpecen o limitan en algunos casos la averiguación de la verdad: así las reglas de exclusión probatoria, la limitación temporal del proceso, la regla de eficacia de cosa juzgada son ejemplos claros de lo indicado" 80 . En este sentido se ha señalado que "(...) en la base de estas y otras variaciones se pueden encontrar siempre explicaciones, especialmente de carácter histórico o razones sistemáticas debidas a la exigencia de tutelar valores considerados como prevalecientes" $"$.

De esta manera, “(...) el criterio de admisibilidad opera únicamente en el sentido de excluir del proceso pruebas que serían relevantes para la determinación de los hechos" 82 . Así las cosas, y como se ha señalado, la razón de existencia de estas reglas de admisibilidad, y su consecuencia, cual es la exclusión de prueba, es evitar errores o actividades procesales inútiles, siendo en algunos casos normas propiamente normas de exclusión y otras más bien meros privilegios.

Dentro de las normas de admisibilidad que buscan evitar errores podemos tomar como ejemplos, la obligación de presentar el documento original, la exclusión del testimonio de oídas o cualquier elemento que per se puede complicar la decisión sobre el hecho litigioso ${ }^{83}$. Por otra parte, en la búsqueda de evitar actuaciones procesales inútiles se pueden mencionar aquellas reglas que tienen por objeto evitar el riesgo de demoras excesivas, pérdidas de tiempo o adquirir pruebas innecesarias que solo se acumulen en el proceso ${ }^{84}$. Por último, respecto a los que Taruffo se refiere como privilegios, lo que se busca claramente es la protección de ciertos valores, como secretos de Estado, privacidad personal o ciertos motivos personales, que como veremos permite que, en el caso de la prueba testimonial, no se declare o se declare de forma especial, y que en nuestro sistema podríamos mencionar que se refieren a la prueba ilícita, y a las excepciones a declarar y comparecer ${ }^{85}$.

\footnotetext{
78 PÁez (2014) p. 114.

79 Del Río (2010) p. 356.

80 Del Río (2010) p. 356.

81 Taruffo (2011) p. 376.

82 Taruffo (2011) p. 364.

83 ZuCKerman (2013) p. 960.

84 Taruffo (2008) p. 50.

${ }^{85}$ Ver también Laudan (2013) pp. 230 ss.
} 


\subsubsection{Agente y producto en la etapa de conformación del material probatorio}

Como se ha señalado durante este trabajo, el análisis de cualquier testimonio, en la etapa de conformación del material probatorio, debe realizarse separadamente entre el agente y su producto. En relación al primero, la pregunta es determinar qué tendremos en consideración para incluir a un determinado agente, para luego hacernos la misma pregunta respecto de lo que aspiramos en relación al producto de la declaración que este prestará.

La primera interrogante que surge, en este análisis distintivo, es quienes pueden ser testigos. En la legislación chilena, de acuerdo a su tratamiento tradicional en la materia, el artículo 365 del CPC señala que "es hábil para testificar en juicio toda persona a quien la ley no declare inhábil”, es decir, per se, son todos hábiles para declarar en juicio, sin perjuicio que en los artículos siguientes del mismo cuerpo legal, se establecen dos listados exhaustivos respecto de quienes son inhábiles para declarar como testigos ${ }^{86}$. La existencia de dos listados, dice relación con que el primero de ellos, el del artículo 357 del Código de Procedimiento Civil, establece lo que han sido llamadas "inhabilidades absolutas", es decir, aquellas personas que nunca podrán declarar en ningún tipo de juicio. Distinto es el caso del artículo 358 del Código de Procedimiento Civil, que enumera a los "inhábiles relativos", quienes por regla general pueden declarar en cualquier juicio, salvo que tengan un tipo de relación con alguna de las partes que pueda catalogarse en dicha norma.

Los listados elaborados en los artículos ya mencionados (357 y 358 CPC), están claramente realizados a partir de concepciones tradicionales respecto al testimonio, y en general a una idea conservadora de la etapa probatoria, porque confunden, sin mayor análisis, las etapas de inclusión y de valoración del material probatorio, lo que tiene como consecuencia que se valore al agente en la etapa de inclusión. Gorphe es claro en esto al señalar que "siempre se han establecido por el legislador recursos para descartar del proceso civil o penal ciertas categorías de testigos que no ofrecían suficientes garantías de credibilidad o especialmente de sinceridad" 87 .

Realizando un examen rápido de la historia que ha precedido a la prueba testimonial, el mismo autor ya indicado, menciona que desde El Libro de la ley de Manú de los pueblos hindúes, no se admite como testigos a los amigos, criados, condenados, locos o gente de mala reputación. De la misma manera, señala que la mayoría de las legislaciones rechazan el testimonio del cónyuge, de ascendientes, descendientes o afines, o en otros casos, los dementes o incapaces ${ }^{88}$. Lo mismo puede verse en el caso chileno, ya que el artículo 357 del CPC menciona como inhábiles a los menores de 14 años; los interdictos por demencia; los privados de razón; los que carezcan del sentido para percibir los hechos declarados al tiempo de verificarse estos; los sordos o sordomudos; los cohechados; los vagos sin ocupación; los que por concepto del tribunal sean indignos de fe por haber sido condenados por delito, y los que hagan de su profesión testificar en juicio.

\footnotetext{
86 Cabe hacer la salvedad que si bien el concepto que hemos entregado de testimonio es amplio, es decir admitiría, por lo menos, a las partes y peritos, para que podamos realizar el primer análisis general nos centraremos en el tratamiento dado a la prueba testimonial tradicionalmente estudiada y así regulada.

87 Gorphe (1985) p. 23.

${ }^{88}$ Gorphe (1985) p. 23.
} 
Si se analizan las causales de inhabilidad "absolutas", podemos observar que el objetivo final es verificar la fiabilidad de un testigo porque estas tienen que ver con la edad, la capacidad mental del testigo, el interés, o la incompetencia del testigo por condenas penales ${ }^{89}$. Es decir, la inclusión o no del mismo apunta no a lo que dirá sino a sus características personales.

Uno de los casos más típicos en relación a un tipo de inhabilidad absoluta es la edad, se ha dicho, que "normalmente los niños pueden ser interrogados como testigos cuando se considera necesario, pero no juran decir la verdad" ${ }^{\prime \prime}$, debiendo el tribunal llevar un control exhaustivo del interrogatorio. Otro ejemplo es en relación a la capacidad, donde se ha señalado que si bien podría incorporarse su testimonio, este puede presentar problemas respecto a la fiabilidad del testimonio ofrecido por esa persona ${ }^{91}$.

El artículo 358 del CPC se refiere a aquellas personas con relaciones familiares (cónyuges, parientes, ascendientes, descendientes), relaciones de guarda (pupilos y guardadores); relaciones laborales (criadores domésticos, dependientes, trabajadores), personas con interés en el juicio o quien tenga relaciones de amistad.

Estas inhabilidades pueden impugnarse, por la parte a la que la perjudica el testimonio, a través de la institución de las tachas. A través de ellas, lo que finalmente se hace es impugnar la credibilidad del testigo, e históricamente se relacionaban con los familiares.

De esta forma, "con la tacha se ataca al testigo porque está en una situación que afecta a su credibilidad. No se trata de destruir la eficiencia probatoria del testimonio, puesto que esta se aniquila con otras pruebas que, versando sobre el mismo hecho, desvirtúen las declaraciones prestadas por los testigos, que tiene apariencia de legalidad y pertinencia, para despojarla de esa apariencia" 92 . Lo anterior, no hace más que ratificar la idea que las tachas -que se centran en el agente-, contaminan el producto de la declaración.

Respecto a las tachas, se ha señalado que su concurrencia no hace que el testigo tachado tenga una inferioridad respecto al no tachado, solo lo hace "sospechoso de credibilidad"93. Esto olvida, “(...) que un adecuado interrogatorio podría hacer prescindibles los detalles objeto de la tacha, haciendo que la declaración de quien fuere, por mayor o menor interés que tuviera en la causa, pudiera ser útil"94.

La explicación que se da, es señalar que en materia civil y en pro de la prevalencia de ciertos valores determinados por el legislador de acuerdo a diversas circunstancias, se ha buscado establecer la existencia de buenos y malos testigos, lo que finalmente trae aparejado otro juicio de valor que es señalar ex ante a qué personas se les podrá creer y a quienes no. Es decir, se anticipa el juicio de credibilidad, y en definitiva la valoración del testigo en sede de admisibilidad por valores previamente establecidos ${ }^{95}$.

En nuestra legislación procesal civil, la confusión entre la etapa de inclusión y la de valoración es clara, así como entre el agente y el producto de su declaración, lo que tiene como

89 TARUFFo (2008) p. 64.

90 Taruffo (2008) p. 63.

91 TARUfFo (2008) p. 63.

92 Rivera (2011) p. 190.

${ }^{93}$ Rivera (2011) p. 266.

${ }_{94}$ Nieva (2010) p. 267.

95 Esta idea se extrae de Ferrer (2007) p. 44. 
consecuencia el que se realice ex ante una valoración del testigo de acuerdo a criterios ya definidos. Esto hace surgir la interrogante de qué pasa si efectivamente se excluye un testigo, ya sea por interés o por su posición, en la primera etapa, pero su testimonio se hace relevante para la decisión del asunto. En materia civil, esto es evidente en varias situaciones, por ejemplo, el familiar o el trabajador de la empresa de una de las partes, por su posición respecto a los hechos, los conoce muchísimos mejor que un tercero. Así las cosa e independiente de ciertos requisitos formales, que pueden discutirse, es posible señalar que todo agente per se debe incluirse en juicio ya que el eventual juicio de su persona se realizará en sede de valoración, en otras palabras, toda persona es capaz de ser testigo si se le requirió así en juicio ${ }^{96}$.

Los efectos de lo anteriormente señalado es que, establecido que todos los testigos son hábiles y por tanto desde el análisis del agente siempre este debe incluirse, cabe realizar, en segundo lugar, el examen respecto a la admisión del producto de su declaración.

Respecto a este segundo punto, cabe señalar que hay legislaciones que establecen como inadmisible la inclusión de una declaración que provenga de conocimientos obtenidos por oídas o referencia ${ }^{97}$. Así, en muchos sistemas se solicita que el testigo realice su declaración solo en referencia a lo que pudo percibir directamente. En algunos sistemas esta inadmisibilidad se justificaría en "evitar el peligro de que los jurados cometan errores al valorar la fiabilidad de la declaración hecha por una persona que no ha tenido contacto directo alguno con el autor de las declaraciones referenciadas y sin haber oído al autor de estas durante el interrogatorio y contrainterrogatorio" ${ }^{98}$.

En Chile, solo en materia civil podemos observar la distinción entre testimonios de oídas y presenciales, pero que no influye en una posible exclusión de dicho testimonio. El artículo 383 del CPC, se refiere a los primeros como aquellos referidos a lo que no ha sido percibido por los testigos por sus propios sentidos y que solo conocen por el dicho de otras personas, distinto a los presenciales que están basados en aquello que percibieron por sus propios sentidos. Como señalé, el testimonio de oídas no es descartable en la etapa de inclusión en nuestro país porque el artículo 383 ya citado no solo los define, sino que establece que dicho testimonio puede ser considerado base de presunción judicial, es decir, lo analiza en lo que correspondería a la etapa de valoración.

Otro aspecto que también se ha tenido en consideración al momento de excluir ciertos testimonios -entendidos como productos-, es el hecho de que sea un testimonio, ya que las pruebas orales tendrían una fiabilidad menor que las escritas ${ }^{99}$. Lo anterior, se produce en ciertos casos muy particulares y solo respecto a la prueba de determinados hechos. El artículo 1708 del Código Civil es claro al señalar que "no se admitirá prueba de testigos respecto de una obligación que haya debido consignarse por escrito", dándose en este caso la paradoja que enunciamos en la introducción, de que la mayoría de los conocimientos

\footnotetext{
96 ZuCKerman (2013) p. 1037.

97 TARUfFo (2008) p. 43.

98 TARUfFo (2011) p. 376.

99 Carnelutti (1982) p. 120. En este mismo aspecto, entendemos que esta apreciación sigue la idea de que los testimonios son orales, porque se podría llegar a un concepto tan amplio que también abarcara todo lo oral y escrito.
} 
que tenemos han sido obtenidos por testimonios, por lo que la mayor fiabilidad del documento escrito presenta claros cuestionamientos.

De esta manera, si las obligaciones emanan de actos y contratos solemnes cuya solemnidad consiste en el otorgamiento de un instrumento público o privado (artículos 1701 y 1682 del Código Civil) y si son actos o contratos que contienen la entrega o promesa de una cosa que valga más de dos unidades tributarias, no podrán probarse a través de testigos (artículo 1709 del Código Civil). En el mismo sentido anterior, el artículo 1709 del Código Civil señala en su inciso $2^{\circ}$ : "No será admisible la prueba de testigos en cuando adicione o altere de modo alguno lo que se expresa en el acto o contrato, ni sobre lo que alegue haber dicho antes, o al tiempo o después de su otorgamiento, aun cuando en algunas de estas adiciones o modificaciones se trate de una cosa cuyo valor no alcance a la referida suma”, aplicándose estas restricciones aún cuando se limite la demanda a la suma de dos unidades tributarias si la cosa es de superior valor (artículo 1710 inciso $1^{\circ}$ del Código Civil) y cuando se demande parte o resto de un crédito de una suma inferior a dos unidades tributarias, si ella proviene de un crédito que debió haberse consignado por escrito (artículo 1710 inciso $2^{\circ}$ del Código Civil).

De forma excepcional, si existe un principio de prueba por escrito o existe imposibilidad de obtener esta prueba escrita, se admitirá el testimonio al respecto, en concordancia con el artículo 1.711 del Código Civil. Al mismo tiempo, sucede lo mismo si se trata de probar el depósito de efectos del que aloja en una posada (Artículos 2.241 y 2.237 del Código Civil) o del que entra a alguna fonda, café, casa de billar o de baños o establecimientos semejantes (artículo 2.248 del Código Civil).

Distinta es la regulación en el ámbito mercantil, porque esto no se aplica a los actos mercantiles por expresa mención del artículo 128 del Código de Comercio: "La prueba de testigos es admisible en negocios mercantiles, cualquiera que sea la cantidad que importe la obligación que se trate de probar, salvo los casos en que la ley exija escritura pública”.

De cierta manera, aunque no sería propiamente un examen de admisibilidad, podrían incluirse aquello que Taruffo denomina privilegios. En nuestro sistema civil se encuentran señalados en los artículos 360, 361 y 362 CPC. El primero, menciona a aquellas personas que no serán obligadas a declarar, las razones de ello son principalmente secretos vinculados a su profesión u oficio y a las relaciones familiares; el artículo siguiente, menciona a quienes sí deben declarar, pero que podrán hacerlo en su domicilio; para terminar, el artículo 362, que mencionado que los chilenos o extranjeros que gocen de inmunidad diplomática no están obligados a declarar ni a concurrir a la audiencia.

Como es posible identificar, respecto a la conformación del material probatorio no hay análisis en nuestra legislación respecto al examen de relevancia y admisibilidad del producto de la declaración que el agente efectuará, lo que en cierta medida sí ha efectuado la doctrina comparada estableciendo ciertas circunstancias para determinan si una declaración será incluida ${ }^{100}$. Solo podemos encontrar a nivel nacional, y en relación a este elemento,

\footnotetext{
100 En materia civil no existe una etapa de admisibilidad, y solo podríamos realizar una especie de asociación con la admisibilidad de testigo, no de su testimonio, a la institución de las tachas vinculadas a inhabilidades (artículos 357 y 358 del Código de Procedimiento Civil).
} 
las excepciones a declarar y a comparecer, que claramente no son propias de un análisis de relevancia y admisibilidad, ya que los testimonios de oídas solo se reglamentan respecto a la valoración, siendo la inadmisibilidad de pruebas orales respecto a ciertos actos jurídicos que deben constar por escrito, el único caso en que, sin señalarlo explícitamente y por no existir una etapa de admisibilidad determinada, se descartaría una declaración. Lo señalado, también deja un velo de incertidumbre porque realmente lo que sucede no es que no se pueda prestar la declaración, sino que el acto determinado no podrá tenerse por comprobado en razón de la misma.

\subsubsection{Etapa de valoración}

El segundo de los momentos de la etapa probatoria es el de la valoración de la prueba, esta etapa “(...) tiene por objeto establecer la conexión final entre los medios de prueba presentados y la verdad o falsedad de los enunciados sobre los hechos en litigio" ${ }^{101}$.

De esta manera, a través de la etapa de valoración se determinará que antecedentes pesarán más que otros, ya sea, mediante las normas de la prueba legal o tasada, o de acuerdo a la libertad probatoria.

Al referirnos a las reglas de la prueba legal o tasada estamos describiendo la valoración de la prueba que efectúa el legislador estableciendo el valor probatorio de cada medio de prueba según las diversas circunstancias. Taruffo lo describe como un sistema basado “(...) en la aplicación de reglas -en algunos casos promulgadas por los legisladores, pero en muchos otros estipuladas por juristas teóricos- que establecían a priori y en términos generales el valor probatorio de algunos tipos de medios de prueba -y a veces de todos ellos" ${ }^{102}$. En cambio, el sistema de valoración libre implica que el juzgador "tiene que determinar el valor probatorio de cada medio de prueba específico mediante una valoración libre y discrecional. Esta valoración tiene que hacerse caso por caso, conforme a estándares flexibles y criterios razonables" ${ }^{103}$.

En el proceso civil chileno, el sistema predominante es el de la prueba legal o tasada con ciertas atenuaciones, rigiéndose por las normas reguladoras de la prueba que establecen los medios de prueba, la oportunidad, el procedimiento para desarrollarlo y su valoración. Así, los artículos 1698 inciso $2^{\circ}$ del Código Civil y 341 del Código de Procedimiento Civil establecen el listado de los medios de prueba; la oportunidad de su rendición, en el caso de la prueba testimonial, la contiene el artículo 320 CPC en relación con el artículo 340 del mismo cuerpo legal, con la excepcionalidad de las medidas para mejor resolver, su desarrollo está determinado por los artículos 363 al 382 CPC, para terminar estableciendo su valoración en los artículos 357 № 1, 383 y 384 CPC.

En materia de valoración de la prueba testimonial, el artículo 357 No 1 del cuerpo legal ya señalado, menciona respecto a los menores de catorce años, que sus declaraciones podrán aceptarse sin previo juramento y estimarse como base para una presunción judicial, cuando tengan discernimiento suficiente. En el caso de los testimonios de oídas, se señala

\footnotetext{
101 Taruffo (2008) p. 132.

102 Taruffo (2008) p. 133

103 TARuffo (2008) p. 135
} 
en el artículo 383 CPC, que solo podrán estimarse como base de presunción judicial, finalizando con el listado de valoración del artículo $384 \mathrm{CPC}$ que enumera la fuerza probatoria de las declaraciones de testigos.

\subsubsection{Agente y producto en la etapa de valoración}

Entendidos los dos grandes sistemas de valoración, volvemos a la necesidad de distinguir entre el agente y el producto de la actividad para la valoración del testimonio. Esta distinción es trascendental nuevamente porque, por ejemplo, “(...) hay sujetos con dificultades gestuales importantes que involuntariamente no actúan en coherencia con lo que están diciendo, y por ello no resultan creíbles a ojos de la sociedad por muy veraz y coherente que sea lo que están afirmando"104. Lo que podría nuevamente recaer en que el agente contaminará la valoración del producto.

En nuestra legislación civil, la regulación respecto a la valoración es algo confusa, porque ex ante hay una valoración de su credibilidad, a través de las tachas, lo que se termina reflejando en los numerales del artículo 384 CPC, donde además el centro siempre está en el testigo y no en lo que este declaró. Esto produce cierta distorsión ya que lo que debiese suceder es valorar al agente y determinar "(...) la ausencia de razones que hagan dudar de la fiabilidad del declarante" 105 , luego analizar el producto de su declaración.

En materia civil, lo anterior es sumamente complejo por dos razones, la primera por la mixtura que se da entre la etapa de inclusión y de valoración, que claramente no se diferencia. Si uno se interioriza en el texto de la ley, el artículo 375 del Código de Procedimiento Civil ${ }^{106}$ este es claro en señalar que la oposición de la tacha no obsta al examen de los testigos por lo que realmente no hay una exclusión de prueba, sino que en la sentencia definitiva, y al ser un procedimiento escrito además, el tribunal valorará la credibilidad del testigo. Es así como Gorphe menciona que para evaluar la valoración del testigo en sí deben analizarse sus aspectos morales, intelectuales, afectivos y psíquicos ${ }^{107}$. Esto es claramente una confusión porque la credibilidad se evalúa en Chile en dos momentos, sin darle al segundo el carácter de valoración propiamente tal.

Si queremos realizar el análisis de la forma separada que planteamos, debemos valorar, respecto al agente, “(...) si el testigo es coherente en toda su explicación y se encontraba casualmente en el lugar de los hechos, hay motivos fundados para considerar que su testimonio es veraz de entrada" ${ }^{108}$. Es decir, la evaluación primaria de la credibilidad del testigo debe ser simple y objetiva, sin poner en duda la misma por posibles vínculos que no deberían influir, en principio, en su declaración posterior.

\footnotetext{
104 Nieva (2010) p. 220.

105 Fernández (2009) p. 106.

106 Artículo 375 Código de Procedimiento Civil: Las tachas opuestas por las partes no obstan al examen de los testigos tachados; pero podrán los tribunales repeler de oficio a los que notoriamente aparezcan comprendidos en alguna de las que señala el artículo 357. La apelación que se interponga en este caso se concederá solo en el efecto devolutivo.

107 Gorphe (1971) p. 85.

108 NiEva (2010) p. 273.
} 
Ahora, de lo anterior, surge la pregunta de ¡cuándo un testigo es confiable?, la respuesta a dicha pregunta ${ }^{109}$, se puede centrar desde dos puntos de vista: reduccionismo o antireduccionismo. Teorías que, sin estar exentas de críticas, nos permitirán aproximarnos a una respuesta.

Así, entendiendo que el testigo es una persona que conoce ciertos hechos que pueden ser relevantes para el desenlace del juicio, no deberíamos descartar ex ante su inclusión, sino que tomarlo en cuenta en la etapa de valoración respecto a su credibilidad como aquí lo planteamos ${ }^{110}$.

La mirada reduccionista estuvo representada por la idea de que confiamos en un testimonio porque la creencia en algún argumento solo radica en la observación del testimonio humano y de que habitualmente los hechos están conformes con lo que han informado los testigos ${ }^{111}$, así Hume mencionaba que “(...) solo la experiencia confiere autoridad al testimonio humano y es la misma experiencia la que nos asegura de las leyes de la naturaleza"112, este planteamiento no estuvo exento de ciertas críticas en el sentido de que dicha afirmación sería falsa si entendemos que la experiencia que nos permite confiar se vincula con la observación individual.

Luego, el planteamiento de Hume no fue suficiente para explicar el por qué confiar en la persona del testigo, y por ende, luego en su testimonio. De esta manera, los reduccionistas contemporáneos establecieron dos condiciones para justificar las creencias: "la primera es que un oyente debe tener razones positivas para aceptar el reporte de un testigo. Estas pueden hacer referencia a evidencia que compruebe que el testimonio es generalmente confiable (reduccionismo global) razones que se refieren a algún reporte particular en un contexto dado (reduccionismo local). La segunda condición es que esas razones no pueden ser testimoniales, so pena de caer en un círculo vicioso. Es en esta segunda condición donde reside realmente el elemento reduccionista, pues el testimonio debe ser reducido a las demás fuentes de justificación epistémica (...)"113.

El problema que presenta esta posición es que, querámoslo o no, en todo ámbito de cosas siempre se termina recurriendo a las evidencias testimoniales, ya que se puede prescindir de otros medios de prueba, como la confesión o algún medio escrito, pero es difícil hacerlo respecto a los testigos ${ }^{114}$. El requisito de no recurrir a razones testimoniales, resulta casi un imposible.

Ante la situación anterior, surge la respuesta de los antirreduccionistas ${ }^{115}$, quienes "afirman que la "observación de la forma en que utilizamos la información testimonial en la vida cotidiana”"116. Luego, si seguimos esta teoría, debemos aceptar el testimonio ajeno

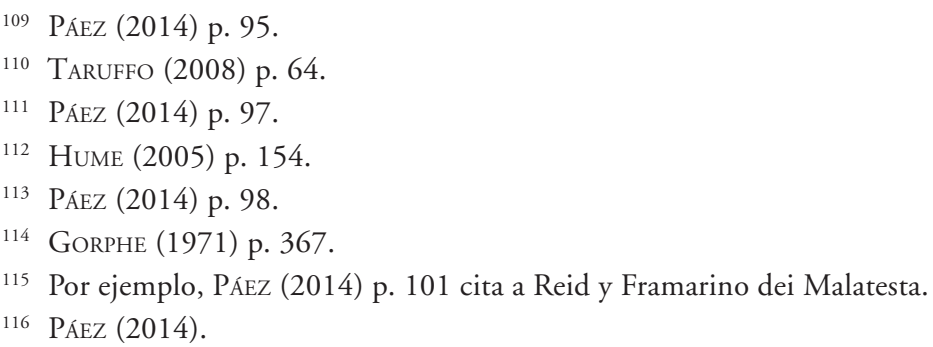


sin verificación alguna, en otras palabras, podríamos confiar sin justificar, hasta que razones sicológicas o normativas nos demostraran lo contrario.

Esta teoría cae en un problema lógico y que surge a simple vista, produce inseguridad y es finalmente una irresponsabilidad epistémica. En otras palabras, conocemos los hechos a través de testimonios que se verificarán a través de otros testimonios en los que vamos a creer.

Así, y como bien resume Páez, nos encontramos ante la tesis reduccionista cuando debamos creer si hay "(...) una mínima justificación para hacerlo”, y ante la tesis antirreduccionista cuando debamos creer "(...) a menos que haya razones más poderosas para no hacerlo" 117 .

De esta manera, es posible concluir respecto al valor de la credibilidad del testigo que no es posible seguir de forma absoluta una tesis u otra, sino que debemos estar al caso concreto respecto a la cantidad de información que se nos entregue. Así, la solución, podrá tener matices reduccionista o antirreduccionistas. No obsta a la conclusión anterior, que los diversos sistemas procesales han seguido el espíritu, conscientemente o no, de alguna de estas dos teorías.

En nuestro sistema civil, podríamos señalar que en general se sigue la teoría reduccionista, aunque muchas veces para demostrar alguna de las causales de inhabilidad que permiten comprobar la parcialidad o el interés, será necesario recurrir a una base eminentemente social de transmisión de conocimiento ${ }^{118}$, o en otras palabras "se demuestra que el espíritu de las normas es reduccionista en el sentido de exigir la presentación de razones positivas para justificar el testimonio del testigo, pero que es imposible pretender que en todos los casos dichas razones puedan ser reducidas a fuentes más básicas y confiables" ${ }^{119}$. Este tema ha sido analizado detalladamente desde la psicología del testimonio ${ }^{120}$, que en parte explicita como detectar mentiras en las declaraciones, lo que es sumamente complejo, pero también, permite analizar la forma de realizar el interrogatorio y obtener la información más relevante.

Determinado que es en materia de valoración donde debe examinarse la credibilidad del testigo, debemos pasar a analizar la valoración del producto de la declaración que realiza e agente. El tema de la valoración específica del testimonio ha sido explicado por Páez como la forma de "buscar una justificación para la afirmación testimonial, encontrando hechos que aumenten la probabilidad de que la afirmación sea verdadera y (ii) determinar si la justificación obtenida en el primer paso es suficiente para la aceptación del testimonio en ese contexto" 121 .

La valoración del producto de la declaración es compleja porque lo que ahí se señale puede tener deformaciones en la percepción de los hechos por temas de tiempo transcurrido, por factores físicos, ideológicos, alteraciones síquicas o falsedad de las declaraciones.

\footnotetext{
117 PÁeZ (2014) p. 101.

118 PÁEZ (2014) p. 106.

119 PÁez (2014) p. 108.

${ }^{120}$ Hay interesantes trabajos al respecto de, por ejemplo, Manzanero (2008); Loftus et al. (2013); Diges (2016); SIIVA et al. (2018).

${ }^{121}$ PÁez (2013) p. 224.
} 
Además, “(...) porque su valoración suele estar presidida por la apreciación judicial de elementos de comunicación de tipo no verbal. (...) En segundo lugar, puede cometer errores motivados por razones tales como los efectos de hechos acaecidos con posterioridad al suceso o un deficiente interrogatorio. Por último (y solo por destacar los más relevantes), a los problemas anteriores hay que sumar las deficiencias sufridas, por un lado, en el proceso de percepción de un suceso (que puede durar desde escasos segundos hasta años), de interpretación del mismo y, por otro, los diversos factores que afectan en mayor o menor grado a la capacidad para recordarlo (fisiológicos, psíquicos, culturales, ambientales, etc.)"122.

Para que una declaración pueda considerarse, a lo menos, verosímil, debe ajustarse a las reglas de la lógica o de la experiencia, o sea, no ser fantasiosa; que en el caso de ser inculpatoria se mantenga en el tiempo, y que pueda ser corroborada por datos objetivos de carácter externo ${ }^{123}$. Esto último, da entender una especie de seguimiento de la tesis reduccionista ya explicitada

Si hacemos un análisis más detallado de nuestra legislación en sede civil, el artículo 357 No 1 del Código de Procedimiento Civil se refiere a la valoración del testigo, independiente del testimonio al señalar: "no son hábiles para declarar como testigos: $1^{\circ}$ los menores de catorce años. Podrán, sin embargo, aceptarse las declaraciones sin previo juramento y estimarse como base para una presunción judicial, cuando tengan discernimiento suficiente". Sin embargo, el artículo 383 del mismo cuerpo legal se refiere al testimonio de oídas, que ya hemos analizado, y en este caso, sí determina la valoración del producto de la declaración porque el contenido de esta estará dado por lo que oyó el testigo.

Luego, la norma más importante en materia de valoración civil de la prueba testimonial se encuentra en el artículo 384 del Código de Procedimiento Civil donde es explícita la falta de distinción entre valoración de testigo y testimonio ${ }^{124}$. De esta norma podemos concluir que claramente existe una confusión entre agente y actividad en Chile, porque si bien se señala que se establecerá el valor o "fuerza probatoria" de las declaraciones de testigos, lo que se termina evaluando es al testigo, y dependiendo de la calidad de tal, el valor que se le otorga a la declaración, o sea, la valoración de la actividad va de la mano del agente.

122 FERNÁNDEZ (2009) p. 104.

123 Fernández (2009) p. 111.

124 Artículo 384 Código de Procedimiento Civil: "Los tribunales apreciarán la fuerza probatoria de las declaraciones de los testigos conforme a las reglas siguientes: 1a. La declaración de un testigo imparcial y verídico constituye una presunción judicial cuyo mérito probatorio será apreciado en conformidad al artículo 426; 2a. La de dos o más testigos contestes en el hecho y en sus circunstancias esenciales, sin tacha, legalmente examinados y que den razón de sus dichos, podrá constituir prueba plena cuando no haya sido desvirtuada por otra prueba en contrario; 3a. Cuando las declaraciones de los testigos de una parte sean contradictorias con las de los testigos de la otra, tendrán por cierto lo que declaren aquellos que, aun siendo en menor número, parezca que dicen la verdad por estar mejor instruidos de los hechos, o por ser de mejor fama, más imparciales y verídicos, o por hallarse más conformes en sus declaraciones con otras pruebas de proceso; 4a. Cuando los testigos de una y otra parte reúnan iguales condiciones de ciencia, de imparcialidad y de veracidad, tendrán por cierto lo que declare el mayor número; 5a. Cuando los testigos de una y otra parte sean iguales en circunstancias y en número, de tal modo que la sana razón no pueda inclinarse a dar más crédito a los unos que a los otros, tendrán igualmente por no probado el hecho; y 6a. Cuando sean contradictorias las declaraciones de los testigos de una misma parte, las que favorezcan a la parte contraria se considerarán presentadas por esta, apreciándose el mérito probatorio de todas ellas en conformidad a las reglas precedentes". 
En definitiva, lo que deberíamos realizar debería ser un análisis de la coherencia y plausibilidad de la declaración ${ }^{125}$, para así determinar el valor del producto de la misma.

Realizadas las valoraciones por separado, es preciso señalar que respecto a la resolución final no hay problema con que se presenten de forma conjunta porque como señala Fernández, “(...) se trata de requisitos que, aisladamente considerados, no permiten concluir por sí solos la atendibilidad de la declaración como suficiente prueba de cargo, sino que se trata de elementos que han de presentarse de manera conjunta, y ni siquiera así se garantiza plenamente la veracidad del testimonio" ${ }^{\prime 26}$.

\section{CONCLUSIONES}

En todos los aspectos de la vida nos basamos en algún tipo de testimonio para adoptar alguna decisión. En el ámbito procesal la forma tradicional de estudiarlo ha sido desde la de aquel tercero que relatará algo que percibió o que le contaron, sin existir un análisis pormenorizado del tema ya sea porque se le da más importancia a la prueba documental y a la pericial o porque el testimonio se transmite de forma oral, desconfiándose de este medio de transmisión en contraste con la escritura.

En este trabajo, se busca dejar de lado la visión restringida y tradicional del testimonio, basado en este caso solo en el análisis de la prueba testimonial, pero que incluso con el concepto amplio que se propone podría llegar a englobar la prueba pericial y la declaración de partes. Finalmente, el testimonio será una forma de comunicación en que se trasmitirá información a una audiencia, distinguiéndose dos elementos en él, cuáles son, el agente que realiza la declaración y el producto de dicha declaración.

Nuestra legislación y doctrina, no se hacen cargo ni de dicho concepto amplio y menos aún, de la distinción planteada entre el agente y el producto de la declaración, lo que luego repercute en un eventual análisis de las distintas etapas de la actividad probatoria. En Chile, en materia civil, no es posible distinguir entre la etapa de inclusión y la de valoración, y al no poder realizar aquello, menos podemos diferenciar al testigo de su declaración dentro de ella. Así, se realiza una especie de examen de credibilidad del testigo a través de las tachas, lo que no es propiamente un examen de inclusión del mismo en el juicio, sino más bien una valoración adelantada del agente o testigo.

Respecto a la etapa de valoración, por regirse esta última por el sistema de prueba legal o tasada, el legislador vuelve a confundir entre el testigo y el producto de su declaración e incluso entre inclusión y valoración. Lo anterior, porque en materia de inhabilidades menciona al menor de catorce años, pero acto seguido le otorga un valor de base de presunción a su declaración; respecto al testimonio de oídas, se refiere a la declaración que se basa en hechos no percibidos por sus propios sentidos y le otorga el mismo valor, para terminar, en el artículo 384 del Código de Procedimiento Civil, señalando el valor de ciertas declaraciones, pero que estará determinado por la credibilidad que otorga el testigo. Es decir, en materia civil, no existe etapa de admisibilidad propiamente tal, confundiéndose la valoración del

125 Coloma et al. (2009) p. 324.

126 Fernández (2009) p. 105. 
agente con el objeto de la institución de las tachas ${ }^{127}$, y luego, en lo que podríamos señalar la valoración misma, entremezclando la valoración de la declaración con la del testigo ${ }^{128}$.

Examinada y criticada la realidad chilena, cabe preguntarse entonces cuál es la propuesta de análisis que debe efectuarse. En primer término, y debiendo distinguirse entre las etapas de conformación del material probatorio y de valoración, debe señalarse que el testigo, como agente, siempre debe incluirse en juicio, es decir todas las personas serán hábiles para declarar. No sucede lo mismo con el examen del testimonio -producto- porque en dicho caso, en la etapa de conformación del material probatorio, cabe establecer si la declaración que realizará es relevante dentro del juicio.

Luego, respecto a la credibilidad del testigo, esto debe ser evaluado en sede de valoración, y diferenciándose del producto de su declaración, esto porque la credibilidad no puede ser evaluada en la etapa de inclusión ya que dicha etapa solo apunta a la relevancia de la prueba y a la cautela de ciertos valores, distinto a la credibilidad que es un tema de valoración.

Siguiendo esa línea surge preguntarse, ¿cuándo el testigo es creíble?, y ¡cómo debemos valorar el producto?

Para responder la primera de las preguntas anteriores, podríamos revisar dos teorías, las del reduccionismo y del antirreduccionismo, las cuales, si bien presentan ciertas soluciones, también tienen ciertas falencias que se hace necesario matizar y que también permiten confundir la valoración del agente y la actividad.

Resuelta la valoración del agente, el centro estuvo en el producto, donde la operación intelectual implica descartar los errores de percepción, y de interpretación del testigo e incluso la interpretación del juzgador; establecer la firmeza y coherencia a lo largo del proceso; corroborarlo por datos objetivos (es decir, que esté avalada por algún hecho, dato o circunstancia externa independiente a la propia declaración), y finalmente conectarlo con datos objetivos para tomar una decisión.

Realizadas las dos operaciones anteriores, valoración de credibilidad del agente y valoración del producto de su declaración, el juzgador podrá extraer conclusiones finales respecto a la materia en juicio.

Como se ha establecido a lo largo de este trabajo, podemos observar que en materia civil existe confusión en los distintos análisis, no pudiendo tener claridad respecto a cuál es el examen que se le realiza al testigo y cuál al producto de su declaración, menos aún en qué etapa de la actividad probatoria estos exámenes se realizan. Más grave aún, la institución de las tachas lo que hace es valorar anticipadamente al testigo, y luego en la etapa de valoración misma confundir eventuales valores de credibilidad con cómo influirían en su declaración.

Así, en el proceso racional que el juez realiza, este debe primero enfocarse en las interrogantes que se le formulen al testigo respecto a su credibilidad, para luego enfocarse en la declaración misma atingente al caso en cuestión, aunque esto implique que los elementos deban presentarse de forma conjunta, como lo analicé de acuerdo a Fernández ${ }^{129}$.

\footnotetext{
127 Artículos 357, 358, 373, 374, 375, 376, 377 del Código de Procedimiento Civil.

128 Artículos 383 y 384 del Código de Procedimiento Civil.

129 Fernández (2009) p. 105
} 
Es por todo lo anterior, que la tendencia debe ser realizar la distinción entre el agente y la actividad y en base a esa diferencia examinar la inclusión y valoración. Realizado aquello pueden establecerse ciertas conclusiones ya que no necesariamente un testigo per se mentiroso realizará una mala declaración ni una declaración atingente al caso será dado por el testigo más creíble, porque de lo contrario, no es posible determinar la falsedad de una declaración siendo la única opción analizar esa declaración de forma objetiva e independiente de la persona del declarante ${ }^{130}$. Todo lo mencionado, va de la mano de un concepto amplio de testimonio como el que se planteó al inicio, porque no solo aquel facilita la distinción entre los elementos señalados, sino que además permitirá absorber otros medios de prueba como testimonio que presentan las mismas características que la prueba testimonial respecto a la confusión entre agente y producto, y que hacen plantearse una posible regulación común o al menos un análisis similar, lo que podrá ser analizado en otro trabajo referido a lo mismo.

\section{BIBLIOGRAFÍA CITADA}

Adler, Jonathan (2017): "Epistemological Problems of Testimony", en ZaLTA, Edwards (editor), The Stanford Encyclopedia of Philosophy, Winter, 2017.

Anderson, Terence; Schum, David y Twinning, William (2015): Análisis de la prueba (Madrid, Marcial Pons).

Carnelutti, Francesco (1982): La prueba civil (Buenos Aires, Ediciones Depalma).

Coady, C.A.J. (2002): Testimony. A philosophical study (Oxford, Oxford University Press).

Coloma, Rodrigo; Pino, Mauricio y Montecinos, Carmen (2009): “Fundamentación de sentencias judiciales y atribución de calidad epistémica a las declaraciones de testigos en materia procesal penal", Revista de Derecho de la Pontifica Universidad Católica de Valparaiso, No 33: pp. 303-344.

Contreras, Cristián (2015): La valoración de la prueba de interrogatorio (Madrid, Marcial Pons).

Diges, Margarita (2016): Testigos, sospechosos y recuerdos falsos. Estudios de psicología forense (Madrid, Editorial Trotta).

Del Río, Carlos (2010): "Dos formas discutibles de poner en duda el carácter cognoscitivo de la aplicación judicial del Derecho penal: el principio del consenso y la garantía de la no agravación punitiva", Revista de Derecho de la Pontificia Universidad Católica de Valparaiso, No 34: 349-383.

Dosi, Ettore (2016): La prueba testimonial. Estructura y función (Lima, ARA Editores E.I.R.L.).

FERnÁndez, Mercedes (2009): "La valoración judicial de las pruebas declarativas", Revista Jueces para la democracia, No 64: pp. 95-116.

FerRer, Jordi (2007): La valoración racional de la prueba (Madrid, Marcial Pons).

FigueroA, Sebastián (2016): "Reconocer y explicar (,) lo que hacemos. Una lectura de la agencia humana desde las observaciones de Ludwig Wittgenstein" en OrmeÑo, Juan

130 Nieva (2010) p. 222. 
(editor), Ensayos, razones y agentes. Ensayos sobre teoría de la acción e imputabilidad juridica y moral (Santiago, Ediciones LOM).

Framarino, Nicola (1995): Lógica de las pruebas en materia criminal (Bogotá, Editorial Temis). GASCÓn, Marina (2013): Estándares de prueba y prueba cientifica (Madrid, Marcial Pons).

GorpHE, Francois (1971): La crítica al testimonio (Madrid, Instituto Editorial Reus S.A., $5^{\mathrm{a}}$ edición).

Gorphe, Francois (1985): Apreciación judicial de las pruebas: ensayo de un método técnico (Bogotá, Temis).

Graham, Peter (1997): "What is testimony", The Philosophical Quarterly, Vol. 47, No 187: pp. 227-232.

GUASTINI, Ricardo (2014): Interpretar y argumentar (Madrid, Centro de estudios Políticos y Constitucionales).

Hume, David (2005): Investigación sobre el conocimiento humano (Barcelona, Atalaya).

LACKEY, Jennifer (1999): “Testimonial knowledge and transmission", The Philosophical Quarterly, Vol. 49, No 197: pp. 471-490.

LaUdAN, Larry (2013): Verdad, error y proceso penal (Madrid, Marcial Pons).

Loftus, Elizabeth; Doyle, James y Dysart, Jennifer (2013): Eyewitness Testimony. Civil and Criminal (San Francisco, LexisNexis).

Losada, Alfonso (2015): "El testimonio como dar la palabra", Teorema, XXXIV/1: pp. 5-18.

Manzanero, Antonio (2008): Psicología del testimonio. Una aplicación de los estudios sobre la memoria (Madrid, Ediciones Pirámide).

Maturana, Cristián y Montero, Raúl (2010): Derecho Procesal Penal (Santiago, Thomson Reuters).

Muñoz, Luis (2001): Fundamentos de prueba judicial civil L.E.C. 1/2000 (Barcelona, J.M. Bosch Editor).

Nieva, Jordi (2010): La valoración de la prueba (Madrid, Marcial Pons).

Niño, Douglas y Marrero, Danny (2015): "El testimonio de un experto. Una perspectiva agentiva" en PÁez, Andrés (coord.), Hechos, evidencia y estándares de prueba. Ensayos de epistemología jurídica (Bogotá, Editorial Kimpres SAS) pp. 185-203.

PÁEZ, Andrés (2014): "La prueba testimonial y la epistemología del testimonio", Isonomía, No 40: pp. 95-118.

PAÉZ, Andrés (2013): “Una aproximación pragmatista al testimonio como evidencia”, en VÁsquEZ, Carmen (Ed.) Estándares de prueba y prueba científica (Madrid, Marcial Pons) pp. 215-238.

Palomo, Diego; Bordalí, Andrés y Cortez, Gonzalo (2014): Proceso civil. El juicio ordinario de mayor cuantía, procedimiento sumario y tutela cautelar (Santiago, Thomson Reuters).

QuintanA, Francisco (2008): "La valoración del interrogatorio de testigos en supuestos específicos: el testigo tachado y el testigo - perito" en ABel Lluch, Xavier, Picó, Joan, Aspectos problemáticos en la valoración de la prueba civil (Barcelona, J.M. Bosch Editor).

Ramos, Vitor de Paula (2018): Prova testemunhal. Do subjetivismo ao objectivismo, do isolamento cientifico ao diálogo com a psicologia e a epistemología (Girona, Universidad de Girona).

Ramos, Vitor de Paula (2019): La prueba testifical (Barcelona, Marcial Pons). 
Rivera, Rodrigo (2011): La prueba: un análisis racional y práctico (Madrid, Marcial Pons).

Schlosser, Markus (2015): “Agency” en Zalta, Edwards (editor), The Stanford Encyclopedia of Philosophy, Fall, 2015.

Silva, Eva; Manzanero, Antonio y Contreras, María José (2018): CAPALIST. Valoración de capacidades para testificar (Madrid, Dykinson S.L.).

STEIN, Alex (2005): Foundations of Evidence Law (Oxford, Oxford Unversity Press).

TARuffo, Michele (2008): La prueba (Madrid, Marcial Pons).

TARUfFo, Michele (2011): La prueba de los hechos (Madrid, Editorial Trotta).

TARUfFo, Michele (2012): Consideraciones sobre la prueba y motivación de la sentencia civil. (Santiago, Editorial Metropolitana, $1^{\text {a }}$ edición).

Thagard, Paul (2005): “Testimony, credibility and explanatory coherence", Erkenntnis, vol. 63, No 3: pp. 295-316.

VAZQUeZ, Carmen (2015): De la prueba cientifica a la prueba pericial (Madrid, Marcial Pons).

ZuCKERMAN, Adrian (2013): Zuckerman on civil procedure: principles of practice (Londres, Sweet \& Maxwell).

\section{NORMAS CITADAS}

Ley No 1.552 de (30/08/1902), que aprueba el Código de Procedimiento Civil. Ley No 19.696 de (12/12/2000), Código Procesal Penal. 